\title{
CONTRIBUIÇÕES DO LABORATÓRIO DE INFORMÁTICA NAS AULAS DE CIÊNCIAS: UM ESTUDO DE CASO DO COLÉGIO ESTADUAL ZICO MONTEIRO
}

\author{
MARIA DIVINA DE JESUS SILVA
}

\section{RESUMO}

SILVA, M. D. J. CONTRIBUIÇÕES DO LABORATÓRIO DE INFORMÁTICA NAS AULAS DE CIÊNCIAS: UM ESTUDO DE CASO DO COLÉGIO ESTADUAL ZICO MONTEIRO. Projeto de Pesquisa. Especialização em Tecnologias Aplicadas ao Ensino de Biologia. Universidade Federal de Goiás: 2015.

O presente trabalho visa demonstrar a importância do uso do Laboratório de Informática como ferramenta no contexto escolar. Uma vez que a sua utilização torna-se indispensável para a prática pedagógica ao contribuir para a eficácia do ensino, o que é essencial para motivação dos alunos em relação a construção dos conteúdos. Assim, a presente pesquisa intenta pontuar quais as vantagens encontradas pelos professores de Ciências ao utilizarem desta estratégia didática, além de averiguar como essa modalidade tem sido usado no Colégio Estadual Zico Monteiro, localizado em Uruana- GO. Para tanto, descreve-se algumas alternativas sendo o laboratório composto por vinte sete computadores, potencialmente mais relevantes e pedagogicamente interessantes para a área de ensino, em contraste com os tipos de atividades fortemente estruturadas e tradicionalmente utilizadas habitualmente pelos docentes.

Foi aplicado um questionário exploratório para verificar se existem propostas ou incentivos para os educadores elaborarem atividades didáticas, que propiciam uma boa utilização de tal tecnologia.

O uso da tecnologia como recurso pedagógico, deve estar cada vez, mais presente na vida do professor e do aluno. Além disso, verificou-se se as atividades didáticas utilizando a informática estão sendo realizadas, e com quais finalidades. Se houveram melhorias no aprendizado dos alunos ou nada acrescentou. Além de dados pessoais como: idade, formação profissional, área de atuação, entre outros. Percebe-se que com a aplicação do Projeto os professores passaram a utilizar mais o laboratório de informática desta unidade.

Palavras-chave: Ensino de Ciências. Tecnologias da Educação. Estratégias Didáticas. 


\section{TÍTULO}

\section{CONTRIBUIÇÕES DO LABORATÓRIO DE INFORMÁTICA NAS AULAS DE CIÊNCIAS: UM ESTUDO DE CASO DO COLÉGIO ESTADUAL ZICO MONTEIRO.}

\section{INTRODUÇÃO}

Este artigo tem por finalidade apresentar os resultados de pesquisa desenvolvida no âmbito do curso de Especialização em Tecnologias Aplicadas ao Ensino de Biologia. . A investigação realizada teve por objetivo explorar o potencial pedagógico do Uso do Laboratório de Informática nas aulas de Biologia, avaliando sua eficácia no processo de assimilação de conhecimentos de biologia.

Atualmente uma das maiores cooperações na utilização da informática na educação está fortemente ligada no contexto escolar, onde os métodos e técnicas de ensinos utilizados tradicionalmente são contestados. O modelo de ensino tradicional, onde o professor é responsável pela transmissão do conhecimento ao aluno, onde o aluno memoriza as informações transmitidas pelo professor. Os métodos e as práticas utilizadas no ensino tradicional, quando comparadas com o panorama atual, parecem não estar em concordância com as mudanças e transformações que ocorrem no mundo, principalmente na questão manifestação da informação e do conhecimento. Através da introdução do novo paradigma na educação, onde os estudantes devem ser ensinados a buscar conhecimento, aprendendo como aprender.

Essas mudanças podem ser apresentadas com a presença do computador, proporcionando condições para o exercício da capacidade de procurar e selecionar informações, resolver problemas e aprender independentemente. O uso do computador na educação, ajudado pelos avanços da tecnologia, conduz suas virtudes em direção à melhoria do processo de ensino-aprendizagem. Sua utilização deve ser planejada, visando coerência com estratégias, métodos e técnicas de ensino, aproveitando suas qualidades de potencial. Por esses motivos foi determinado como objetivo geral desta pesquisa: "Realizar um estudo sobre formas de utilização do laboratório de informática do Colégio estadual Zico Monteiro na educação, como ferramenta alternativa e auxiliadora no processo ensino-aprendizagem, pesquisando os professores os métodos empregados através de seu uso, buscando realizar um confronto entre novos conceitos e o tradicional método de ensino". 
A pesquisa iniciou-se com um levantamento de dados de como é utilizado o Laboratório da Unidade Escolar. Feito isso, realizou-se uma breve entrevista com os Professores de Ciências, visando verificar se existem propostas ou incentivos para os professores de Ciências elaborarem atividades didáticas, se propiciam uma boa utilização de tal tecnologia. A coleta de dados foi feita junto aos professores por meio do questionário, visando esclarecer sobre o manuseio dos equipamentos de informática.

Além disso, verificou-se se as atividades didáticas utilizando a informática estão sendo realizadas, e com quais finalidades. Se houveram melhorias no aprendizado dos alunos ou nada acrescentou. Além de dados pessoais como: idade, formação profissional, área de atuação, entre outros. 


\section{O USO DO LABORATÓRIO COMO FERRAMENTA PARA O ENSINO DE CIÊNCIAS}

Vejamos então algo do uso, em contextos educacionais, de pacotes aplicativos genéricos como processadores de texto, gerenciadores de bancos de dados, planilhas eletrônicas etc. Normalmente, não se considera o uso desses aplicativos como tendo importante significado pedagógico. Contudo, muitos educadores e muitas escolas têm concluído que seu uso não só é uma maneira interessante e útil de introduzir os alunos ao computador, como é um excelente recurso para prepará-los para o uso regular do computador em suas vidas.

Computador não é mais o instrumento que ensina o aprendiz, mas a ferramenta com a qual o aluno desenvolve algo, e, portanto, o aprendizado ocorre pelo fato de estar executando uma tarefa por intermédio do computador. Estas tarefas podem ser a elaboração de textos, usando os processadores de texto; pesquisa de banco de dados já existentes ou criação de um novo banco de dados; resolução de problemas de diversos domínios do conhecimento e representação desta resolução segundo uma linguagem de programação; controle de processos em tempo real, como objetos que se movem no espaço ou experimentos de um laboratório de física ou química; produção de música; comunicação e uso de rede de computadores; e controle administrativo da classe e dos alunos. (VALENTE, 1998)

A existência de recursos tecnológicos permite coletar e fazer uso das informações com maior facilidade e eficiência, ou seja, torna-se possível capturar, armazenar, organizar, pesquisar, recuperar e transmitir saberes. Os recursos tecnológicos podem ser classificados segundo sua funcionalidade, dentre as quais podem ser destacadas: ferramentas para análise, avaliação e transformação; ferramentas para interação e comunicação interpessoal e ferramentas para o suporte à aprendizagem.

O uso do computador na escola só faz sentido na medida em que o professor o considerar como uma ferramenta de auxílio e motivadora à sua prática pedagógica, um instrumento renovador do processo ensino-aprendizagem que lhe forneça meios para o planejamento de situações e atividades simples e criativas e que, consequientemente, lhe proporcione resultados positivos na avaliação de seus alunos e de seu trabalho. A capacitação dos professores em uma escola é de fundamental importância para a efetiva integração do computador com as atividades escolares. Parece-nos premente continuar mudando a 
educação, porém, esta ação deve ser contínua e fruto da reflexão de professores e alunos, e não uma imposição do sistema educacional.

Este novo professor deve desenvolver novas competências e habilidades em seus alunos, tornando-os capazes de sobreviver num mundo globalizado e fazendo-os perceberemse como construtores das suas próprias histórias, capazes de aprender a aprender, numa atualização constante, na qual a imagem da TV, do vídeo e do computador tem papel significativo. A Informática Educacional é o processo que coloca o computador e sua tecnologia a serviço da educação.

Portanto, todos os aspectos e as variáveis neste processo deverão estar subordinados à consideração de que a essência da Unidade escolar é de natureza pedagógica, buscando assim melhorias dos processos de ensino-aprendizagem de forma a levar o aluno a aprender, e o professor a orientar e auxiliar esta aprendizagem, tornando-o apto a discernir sobre a realidade e nela atuar. A introdução de computadores na escola, somente como uma nova tecnologia instrumental, não irá resolver, por si, problemas já diagnosticados, como falta de interesse, concentração e disciplina em sala de aula que refletem, muitas vezes, na repetência e evasão escolar.

O computador só terá um real valor quando o professor, após dominar o sistema computacional, encontrar sua melhor utilização dentro de sua área ou disciplina para a realização de trabalhos individuais ou em grupos, diversificados ou integrados, proporcionando ao aluno um atendimento simultâneo e cooperativo, como possibilidades de uma imediata retroalimentação, o que facilita a tarefa de avaliação global de todos os componentes envolvidos neste dinâmico e diferente processo de construção de novos conhecimentos.

A linguagem logo é quando o aluno constrói algo de seu interesse, onde seu aprendizado é através do fazer, o qual esta bastante motivada por colocar a mão na massa. Onde o aprendiz constrói algo através do computador, ou seja, o computador como ferramenta de aprendizagem. Ainda permanece como desafio. Essa integração exige que o educador conheça em profundidade, tanto a linguagem de programação em si, possibilidades e limites, quanto o conteúdo que pretende desenvolver com seu auxílio. A nosso ver, a grande contribuição da Linguagem Logo para a Informática na Educação foi a de explicitar a importância do ciclo reflexivo, envolvido no ato de programação do computador, no processo de aprendizagem (VALENTE 1993).

A fundamentação teórica que apóia este ponto de vista pressupõe uma interação ativa do aluno com a tecnologia para construir seu conhecimento. Neste caso, a tecnologia 
atua como um dos componentes deste processo e não como foco, elemento principal. Sob esta ótica teórica, a integração da tecnologia no processo educativo é vista como um processo ativo, construtivo, onde o aluno gerencia estrategicamente os recursos disponíveis para criar novo conhecimento, mediante extração de informações do meio ambiente e as integrando com os conhecimentos já incorporados ao seu saber.

É preciso também considerar o contexto pedagógico, social e as maneiras como as tecnologias são integradas a eles, porque elas podem ter um grande impacto na maneira como as pessoas pensam e aprendem, podendo inclusive não interferir no processo de aprendizagem.

\subsection{A Escola e a Informática}

No entanto, Mattar observa que essas habilidades parecem não estar sendo valorizadas nas escolas, sendo o game e a diversão deixados do lado de fora enquanto os sistemas educativos perpetuam a separação de um mundo de coisas que se faz "dentro e fora da escola". Para ele, as ações presentes nos games permitem que os jogadores possam ressignificar imagens e objetos de outros games, usando suas descobertas anteriores na manipulação de situações atuais. Explorando o mundo do game, as regras se tornam aparentes e, à medida que joga, o jogador vai aprendendo. $\mathrm{O}$ autor vê esse comportamento como algo peculiar dessa geração dos "nativos digitais", caracterizando seus estilos de aprendizagem com base em ações interativas e colaborativas e, em seu livro, literalmente convida outros autores e pesquisadores para conversarem com ele sobre esse assunto, buscando respaldo teórico e científico para o que ele entende ser o modo com que os nativos digitais aprendem.

Em síntese, a presença das TIC tem sido investida de sentidos múltiplos, que vão da alternativa de ultrapassagem dos limites postos pelas "velhas tecnologias", representadas principalmente por quadro-de-giz e materiais impressos, à resposta para os mais diversos problemas educacionais ou até mesmo para questões socioeconômico-políticas (BARRETO, 2004). Navegar na Internet pode ser um processo de busca de informações que podem ser transformadas em conhecimento, gerando um rico ambiente interativo facilitador e motivador de aprendizagem, bem como pode ser um dispersivo e inútil coletar de dados sem relevância que não agregam qualidade pedagógica ao uso da rede.

Os recursos tecnológicos de apoio ao ensino por si só não promovem mudanças, mas a forma como são utilizados é que pode provocá-las. Internet possibilita a aprendizagem 
pela colaboração, os alunos dos cursos estarão imersos num novo ambiente mediado por uma tecnologia que possibilita o estabelecimento de interações em tempo real desenvolvendo várias conexões internas e externas. (RODRIGUES et.al. 2010).

Assim, cabe ao professor, profissional responsável pelo planejamento, desenvolvimento e avaliação dos processos de aprendizagem sob responsabilidade da escola, orientar os alunos no uso da Internet de modo que os conduza ao processo de construção do conhecimento.

\subsection{Metodologia}

A fim de apresentar o plano de investigação atendo para a qualidade e rigorosidade de um trabalho científico e assim, explanar as escolhas feitas durante o percurso da pesquisa, foram apresentadas algumas considerações referentes ao cunho, a abordagem, bem como as etapas do percurso através da explicitação da coleta e da análise de dados utilizados neste trajeto.

Entende-se de acordo com Lüdke e André (1986), que a pesquisa possui caráter qualitativo, pois, há de interpretar a fala, a escrita, os gestos e as ações de professores e de alunos. Logo, há de considerar o significado dos dados coletados predominantemente descritivos e, portanto, serão valorizados os aspectos subjetivos, como os motivos, o contexto e as particularidades.

Para tanto, quando se propõe uma investigação, entende-se que há um caminho a percorrer. Assim, opta-se pela abordagem do estudo de caso, que consoante Chizzotti (1995, p. 102), representa "a pesquisa para coleta e registro de dados de um ou vários casos, para organizar um relatório ordenado e crítico ou avaliar analiticamente a experiência com o objetivo de tomar decisões ou propor ação transformadora." Prontamente, refere-se a um estudo profundo e exaustivo de um ou de poucos objetos para permitir um amplo e detalhado conhecimento. Assim, compreendendo que é uma abordagem que considera uma unidade como um todo, geralmente incluindo o desenvolvimento dessa unidade, a pesquisa iniciará com um levantamento de dados de como é utilizado o Laboratório de Informática do Estadual Zico Monteiro.

Deste modo, para subsidiar a investigação optar-se-á por instrumentos de coleta de dados que possibilitam evidenciar os fatos, para tanto, será privilegiado o questionário exploratório (Apêndice A). Esse instrumento de coleta de dados consistiu em uma série 
ordenada de perguntas abertas, fechadas e mistas, organizado de acordo com as propostas de Marconi e Lakatos (2003).

A finalidade do questionário exploratório é de verificar se existem propostas ou incentivos para os educadores elaborarem atividades didáticas, que propiciam uma boa utilização de tal tecnologia. Porém, as explicações a respeito da natureza da pesquisa e sua relevância foram informadas através da Carta de Apresentação da Pesquisa e do Termo de Consentimento Livre e Esclarecido (TCLE) que se encontram presentes nos apêndices B e C respectivamente.

Depois que os questionários exploratórios forem aplicados, estes passarão por uma tabulação e por uma análise conforme Bardin (2010), que consiste numa ferramenta de análise das comunicações através da descrição do conteúdo, seguida de técnicas sistemáticas e objetivas, aliada a dedução lógica e justificada de conhecimentos através das mensagens.

\section{USO DO LABORATÓRIO DE INFORMÁTICA: OPORTUNIDADES E DESAFIOS.}

De acordo com os dados coletados nos questionários que foram aplicados a cinco docentes da disciplina de ciências e biologia do Colégio Estadual Zico Monteiro, onde podemos retirar informações importantes que nos auxiliam quanto à análise do perfil desses profissionais e como objetivo principal, podemos verificar como se dá o uso do laboratório por cada um deles, informações extremamente relevantes para nos levar a uma conclusão sobre o tema proposto.

Dessa forma, a análise de dados nos fornecerá informações quanto ao perfil dos docentes (idade, tempo de conclusão da última graduação, tempo de experiência no magistério, titulação, área de atuação, rede de ensino na qual atua) sua capacitação na área de informática (a capacitação na área de informática recebida na graduação, auto-avaliação com relação ao conhecimento em informática, conhecimento de softwares, motivação para capacitação em informática, última capacitação realizada em informática) e, também, sobre a utilização do laboratório de informática para ministrar de suas aulas (utilização do laboratório de informática na escola, finalidade da utilização do laboratório de informática, motivo da não utilização do laboratório de informática, tipo de atividade desenvolvida no laboratório de informática, melhora dos alunos com a utilização do laboratório de informática). 


\subsection{Características Segundo a Idade}

Com a intenção de conhecer o perfil dos professores, uma das características analisadas é a idade, característica esta que nos auxilia a construir o modelo de professor que temos hoje. Como podemos verificar, a maior parte dos professores tem entre 40 e 49 anos.

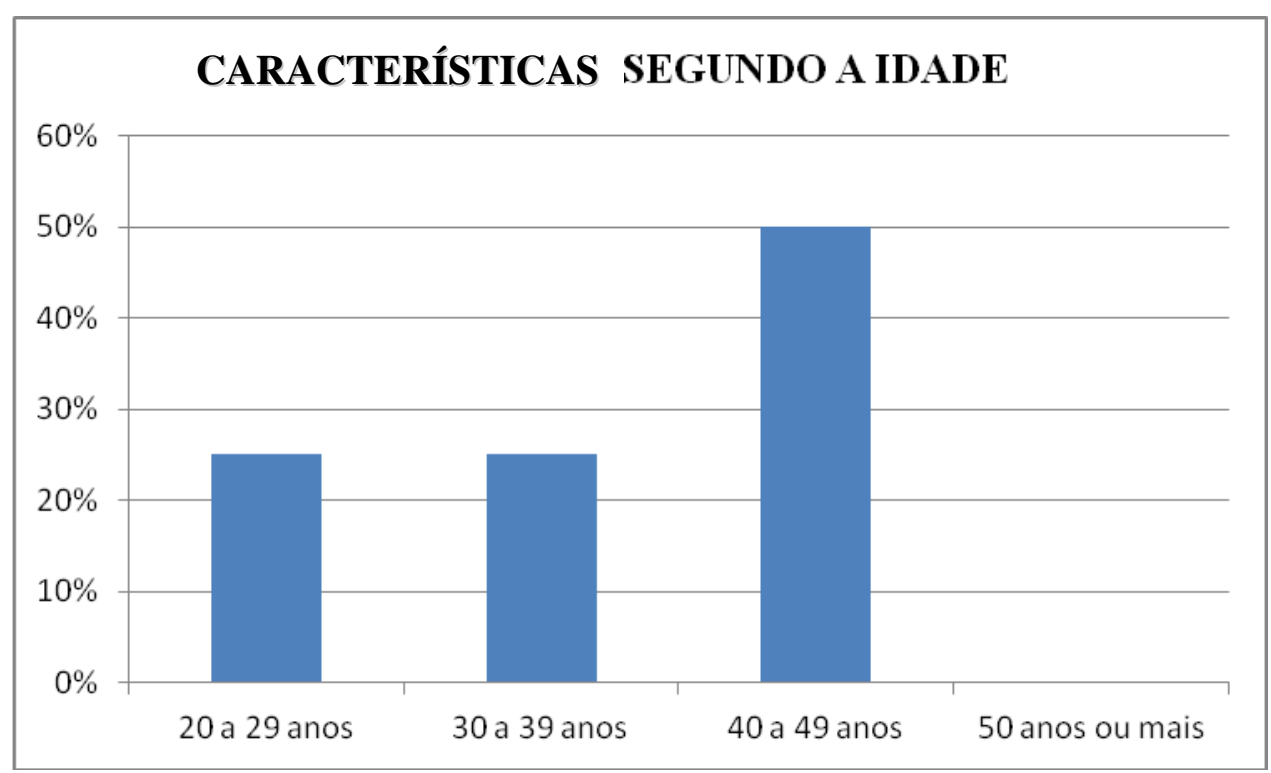

Gráfico 1 - Características Segundo a Idade.

Fonte: Elaborado pelo autor, 2015.

Observa-se que $25 \%$ dos professores têm entre 20 a 29 anos, $25 \%$ entre 30 a 39 anos e $50 \%$ têm entre 40 a 49 anos, sendo que não possui nenhum professor com 50 anos ou mais.

\subsection{Características Segundo o Tempo de Conclusão do Curso de Graduação}

Identificar o tempo que o professor concluiu a graduação nos auxilia a identificar o quanto o professor está voltado para um ensino tecnológico ou não, pois é fato, que aqueles que concluíram a graduação há menos tempo, foram direcionados para uma educação onde o uso da tecnologia é de fundamental importância dentro da sala de aula.

Podemos verificar que a maioria dos professores, $50 \%$, concluíram a graduação a pouco tempo, de 6 a 15 anos. 


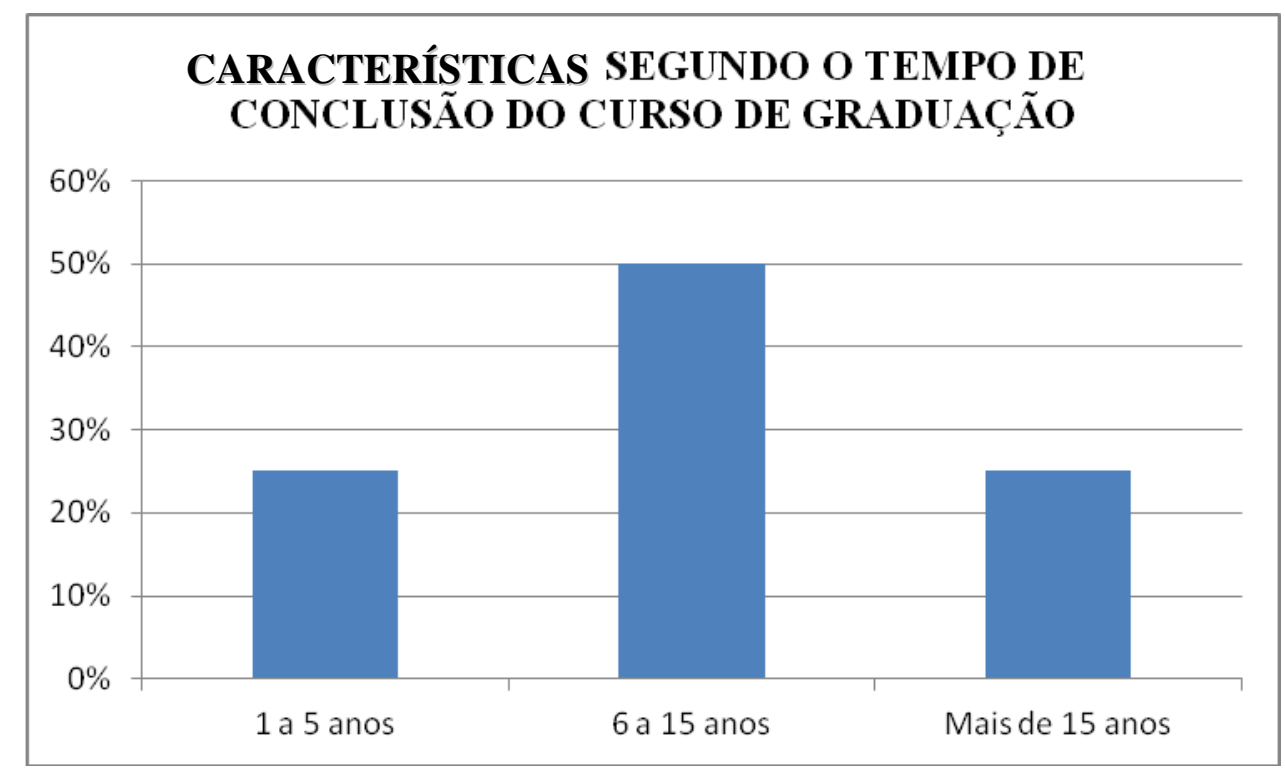

Gráfico 2 - Características Segundo o Tempo de Conclusão do Curso de Graduação. Fonte: Elaborado pelo autor, 2015.

Pode-se observar que $25 \%$ dos professores concluíram o curso de graduação entre 1 a 5 anos atrás, $50 \%$ entre 6 a 15 anos atrás e $25 \%$ a mais de 15 anos.

\subsection{Características Segundo o Tempo de Experiência no Magistério}

Um dos fatores que muito define o perfil do educador é o tempo de atuação no magistério, é fato que quanto mais tempo se atua na área, maior é a experiência do profissional. Analisando o gráfico, pode-se verificar que a maioria dos docentes tem experiência de 1 a 5 anos no magistério.

Importante ressaltar que quando se falar em experiência, não se está dizendo que os profissionais que atuam a menos tempo no magistério tem menor capacidade, apenas se está dizendo que os que atuam a mais tempo tem maior experiência. 


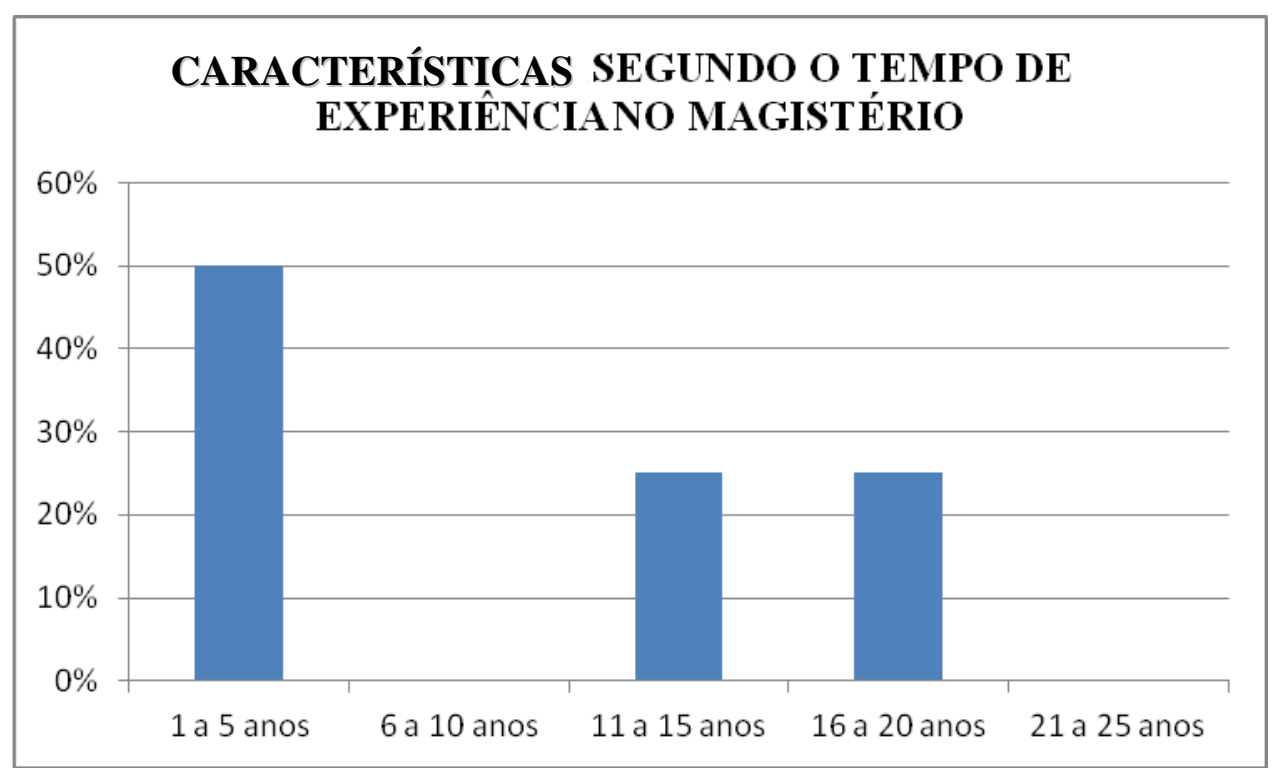

Gráfico 3 - Características Segundo o Tempo de Experiência no Magistério. Fonte: Elaborado pelo autor, 2015.

Verifica-se que $50 \%$ dos professores têm de 1 a 5 anos de experiência na profissão do magistério, $25 \%$ de 11 a 15 anos e $25 \%$ de 16 a 20 anos, sendo que as outras faixas de tempo de experiência apresentaram freqüência de $0 \%$.

\subsection{Características Segundo a Formação Profissional (Titulação)}

Outro fator importante a ser analisado é sobre a titulação do profissional, o quanto ele se dedicou para adquiri conhecimento na área de atuação. Fato é que quanto maior a titulação do educador, mais ele tem a contribuir para a formação acadêmica de seus educandos. 


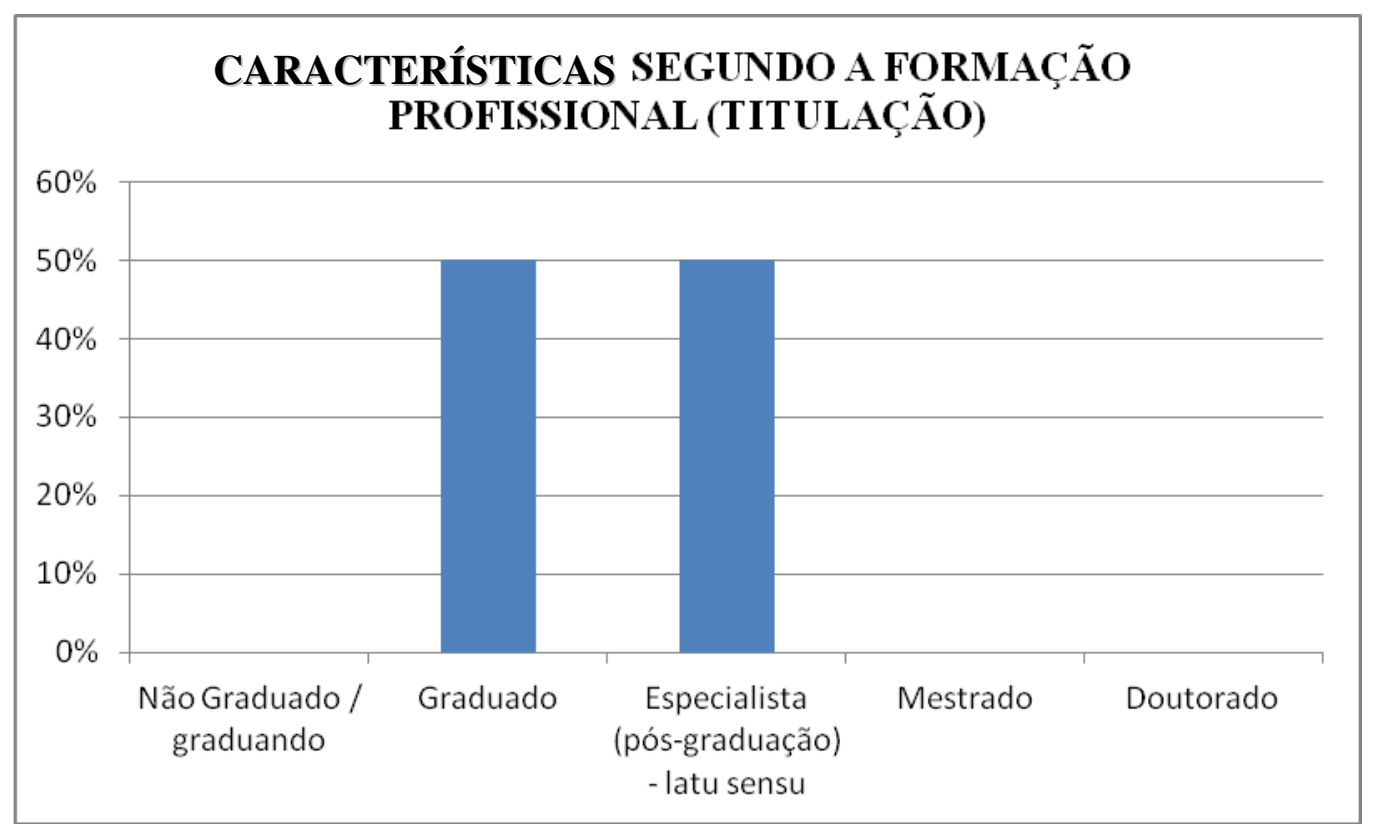

Gráfico 4 - Características Segundo a Formação Profissional (Titulação).

Fonte: Elaborado pelo autor, 2015.

De acordo com o gráfico pode-se verificar que $50 \%$ dos professores são graduados e $50 \%$ são especialistas, ou seja, possuem pós-graduação, sendo que nenhum possui formação a título de mestrado ou doutorado.

\subsection{Características Segundo a Área de Atuação}

Ao se analisar a área de atuação na qual o professor está inserido, podemos supor o grau de conhecimento que o mesmo precisa ter sobre o tema proposto. Bem se sabe que os educandos estão cada dia mais especializados quando se fala em informática, embora o conhecimento que eles têm seja de forma indireta, pois a maioria não cursa escolas especializadas no assunto, é necessário que o educador tenha também, conhecimento para estar, pelo menos, junto com os educandos.

Podemos ver que a maioria dos educadores entrevistados atuam nas séries finais do ensino fundamental. 


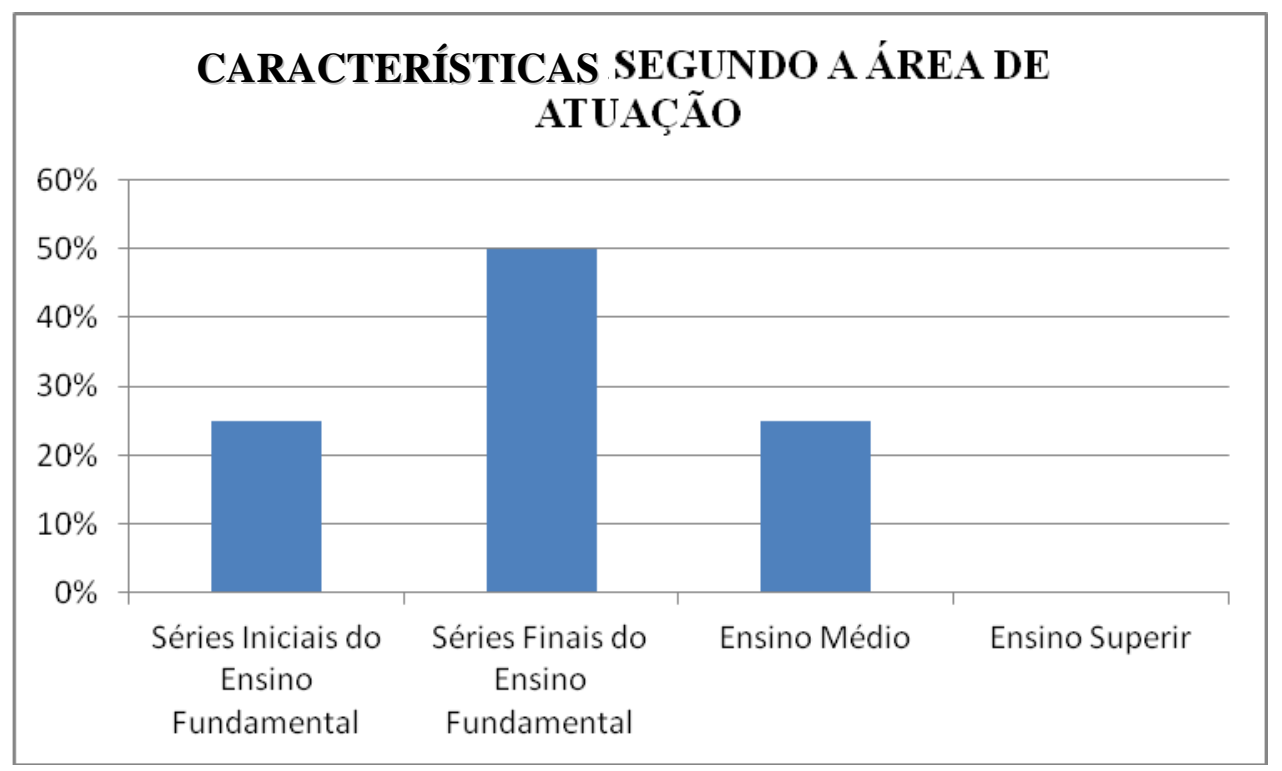

Gráfico 5 - Características Segundo a Área de Atuação.

Fonte: Elaborado pelo autor, 2015.

Verifica-se que $25 \%$ dos professores atuam nas séries iniciais do ensino fundamental, $50 \%$ atuam nas séries finais do ensino fundamental e $25 \%$ atuam no ensino médio.

Ao se analisar os questionários, observa-se que todos os professores que atuam nas séries finais do ensino fundamental também atuam no ensino médio.

\subsection{Características Segundo a Rede de Ensino em que Atua}

Quando se analisa a rede de ensino que o professor atua, pode-se tirar conclusões a respeito da sua realidade em sala de aula, e as possibilidade que esse professor tem para estar trabalhando o tema proposto que é a utilização do laboratório de informática.

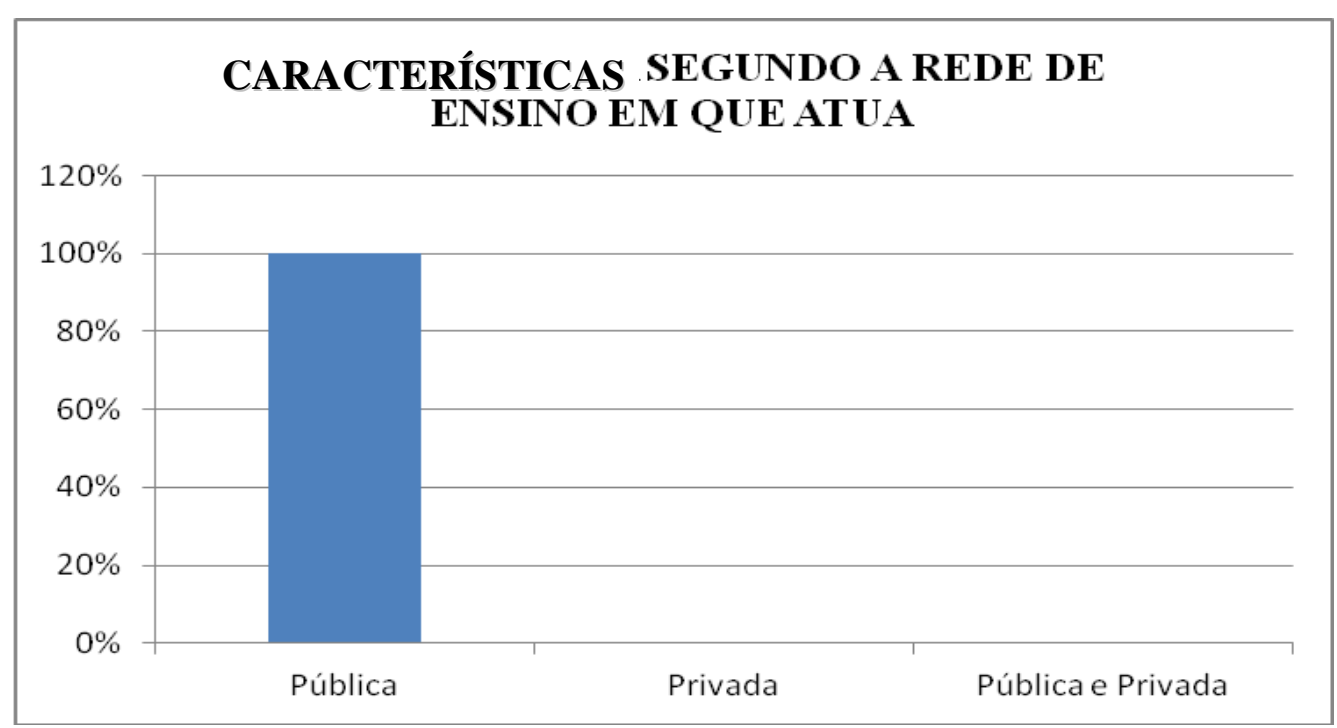


Gráfico 6 - Características Segundo a Rede de Ensino em que Atua.

Fonte: Elaborado pelo autor, 2015.

Observa-se que $100 \%$ dos professores atuam na rede pública de ensino.

\subsection{Características Segundo a Capacitação na Área de Informática Recebida na Graduação}

A capacitação que o educador possui é o que define a utilização e a eficiência de uma aula onde se utiliza o laboratório de informática. Sem qualificação é impossível a utilização do laboratório de informática, a não ser que se possua um profissional especializado e disponível para auxiliar na utilização desse recurso, mas, como podemos verificar $100 \%$ dos educadores pesquisados atuam na rede pública de ensino, e, bem se sabe que ter um profissional disponível par auxiliar na utilização do laboratório de informática não condiz com a realidade na educação na rede pública de ensino.

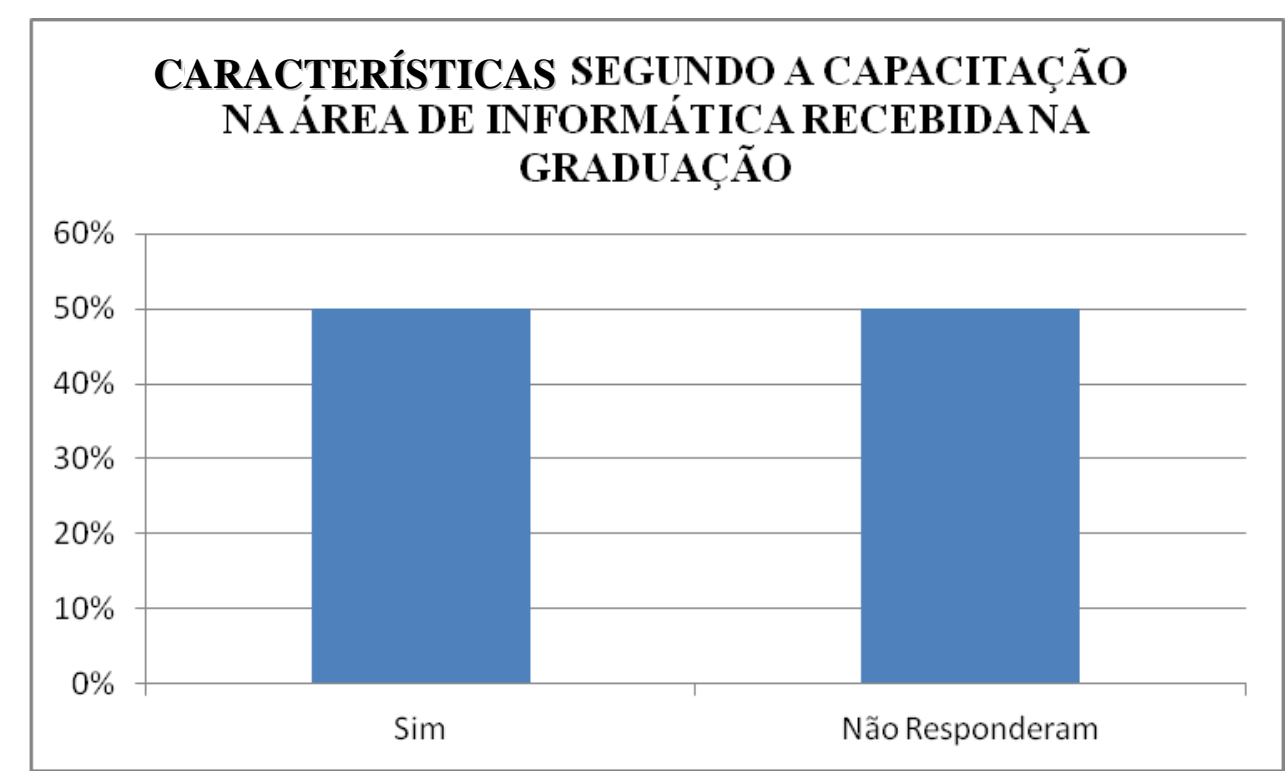

Gráfico 7 - Características Segundo a Capacitação na Área de Informática Recebida na Graduação. Fonte: Elaborado pelo autor, 2015.

Ao se analisar o gráfico, verifica-se que $50 \%$ dos professores receberam capacitação na área de informática durante a graduação e 50\% não responderam.

Dos professores que receberam formação, através da análise dos questionários, observou-se que a formação dos mesmos se deu através de aulas presenciais durante a graduação. 


\subsection{Características Segundo a Auto-avaliação com Relação à Informática}

A informação obtida através das respostas dessa pergunta nos permite verificar a confiança com que o professor utiliza o laboratório de informática, levando em consideração que a falta de segurança quanto ao conhecimento da utilização de alguns recursos tecnológicos é um dos principais motivos da não-utilização do laboratório de informática.

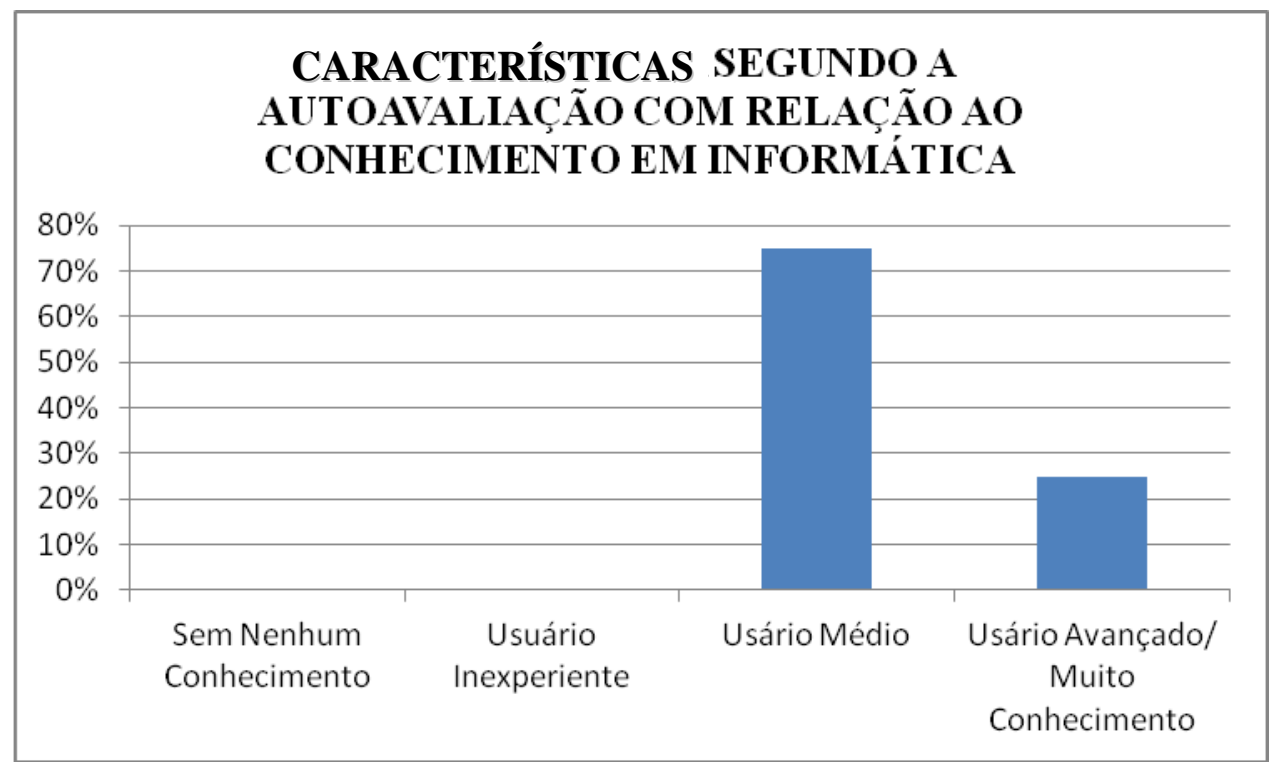

Gráfico 8 - Características Segundo a Autoavaliação com Relação Ao Conhecimento em Informática. Fonte: Elaborado pelo autor, 2015.

Observa-se pelo gráfico que $75 \%$ dos professores se consideram usuários médios com relação à informática e $25 \%$ se consideram usuários com muito conhecimento na área.

\subsection{Características Segundo o Conhecimento de Softwares}

O conhecimento que o educador possui com relação aos softwares, bem como a utilização dos hardwares, é de fundamental importância para a boa ministração de aulas que utilizem o laboratório de informática, portanto, analisando o conhecimento que o educador possui com relação a esses quesitos pode-se definir a qualidade de uma aula no laboratório de informática. 


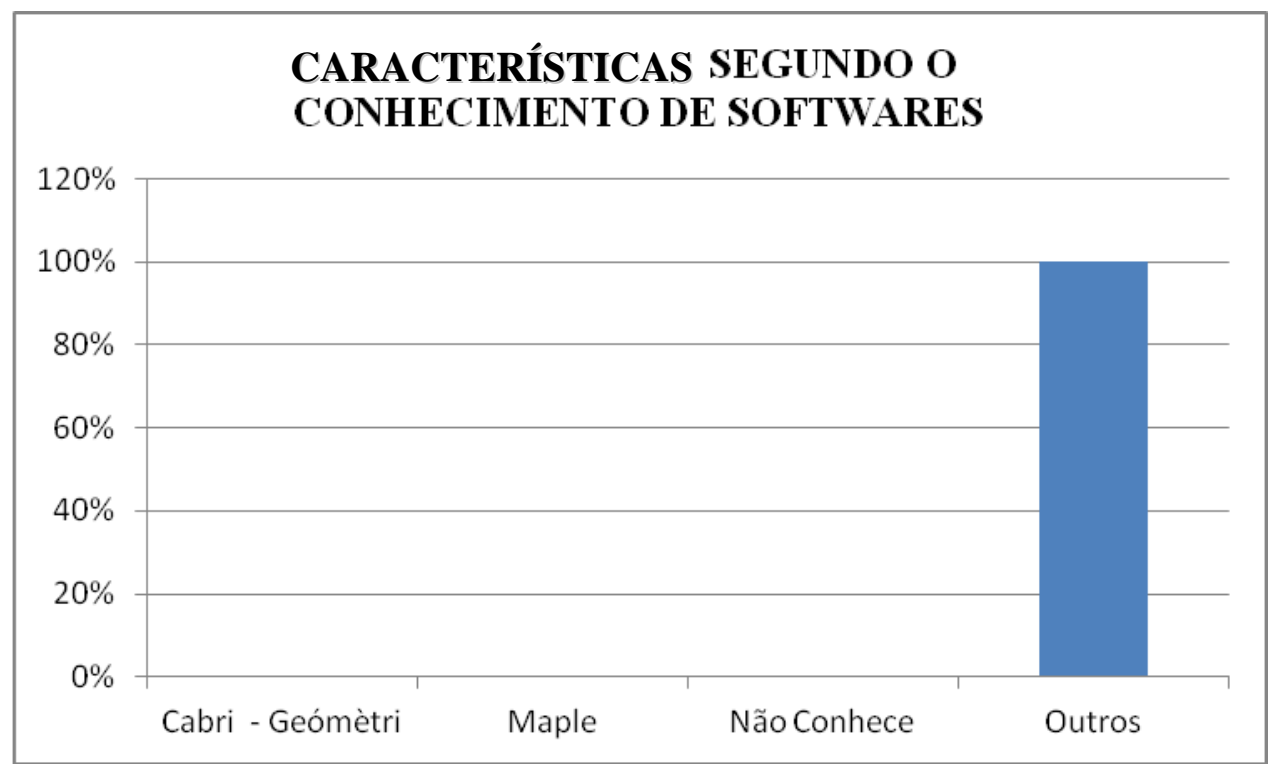

Gráfico 9 - Características Segundo o Conhecimento de Softwares.

Fonte: Elaborado pelo autor, 2015.

Ao se observar o gráfico, verifica-se que os professores não conhecem os softwares citados no questionário. Todos os professores, ou seja, 100\% da amostra conhecem softwares como: Power Point, games, Microsoft Excel, Word, dentre outros, e os utilizam na elaboração de atividades, slides de aulas e planilhas.

\subsection{Características Segundo a Utilização do Laboratório de Informática na Escola}

É importante identificar se o laboratório de informática é utilizado na escola, visto que é um instrumento que contribui para o processo de ensino aprendizagem do educando, outras perguntas irão complementar esta para que se possa tirar conclusões mais precisas sobre a utilização do laboratório de informática. 


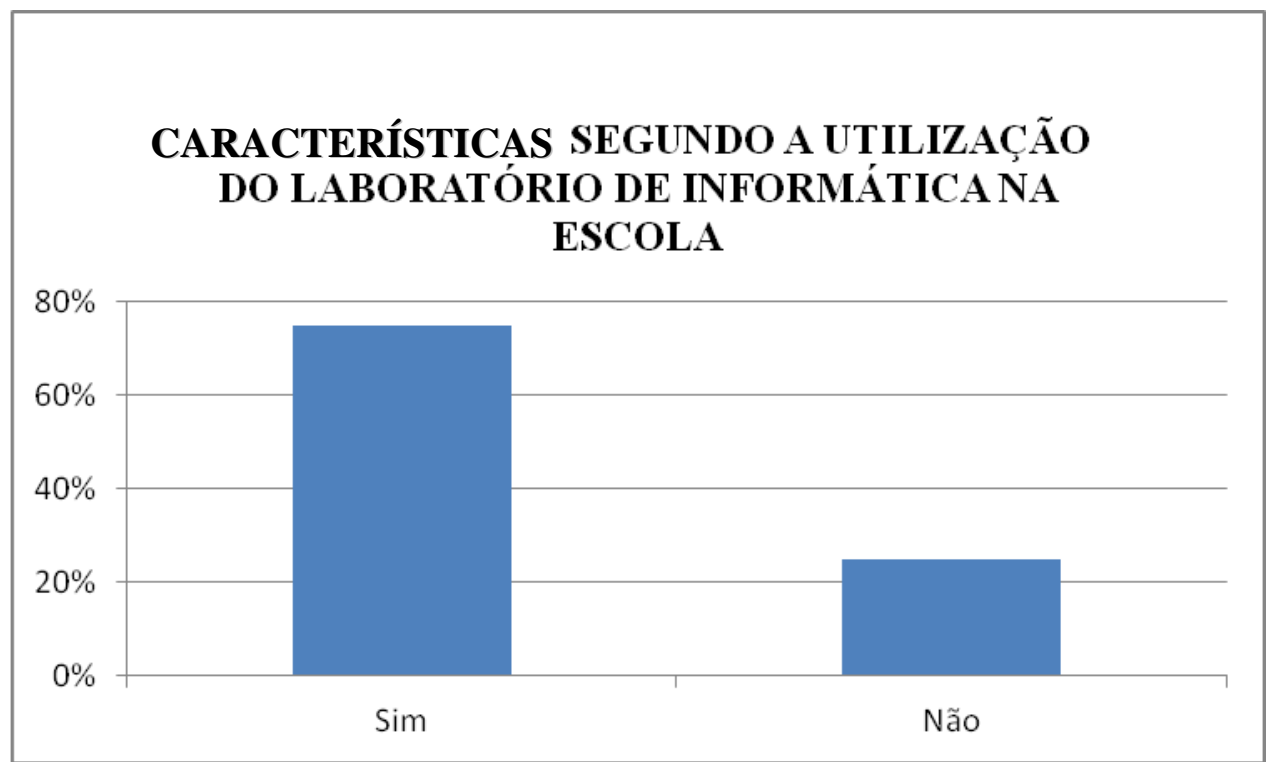

Gráfico 10 - Características Segundo a Utilização do Laboratório de Informática na Escola. Fonte: Elaborado pelo autor, 2015.

Observa-se que $75 \%$ dos professores utilizam o laboratório de informática e $25 \%$ não utilizam o laboratório.

\subsection{Características Segundo a Finalidade da Utilização do Laboratório de Informática}

O professor deve utilizar o laboratório tendo em vista o benefício dos educandos e não para fins pessoais, portanto, a utilização do laboratório deve ser dar apenas para fins didáticos, como pesquisas de atividades, para digitar avaliações, pesquisas de projetos, etc. 


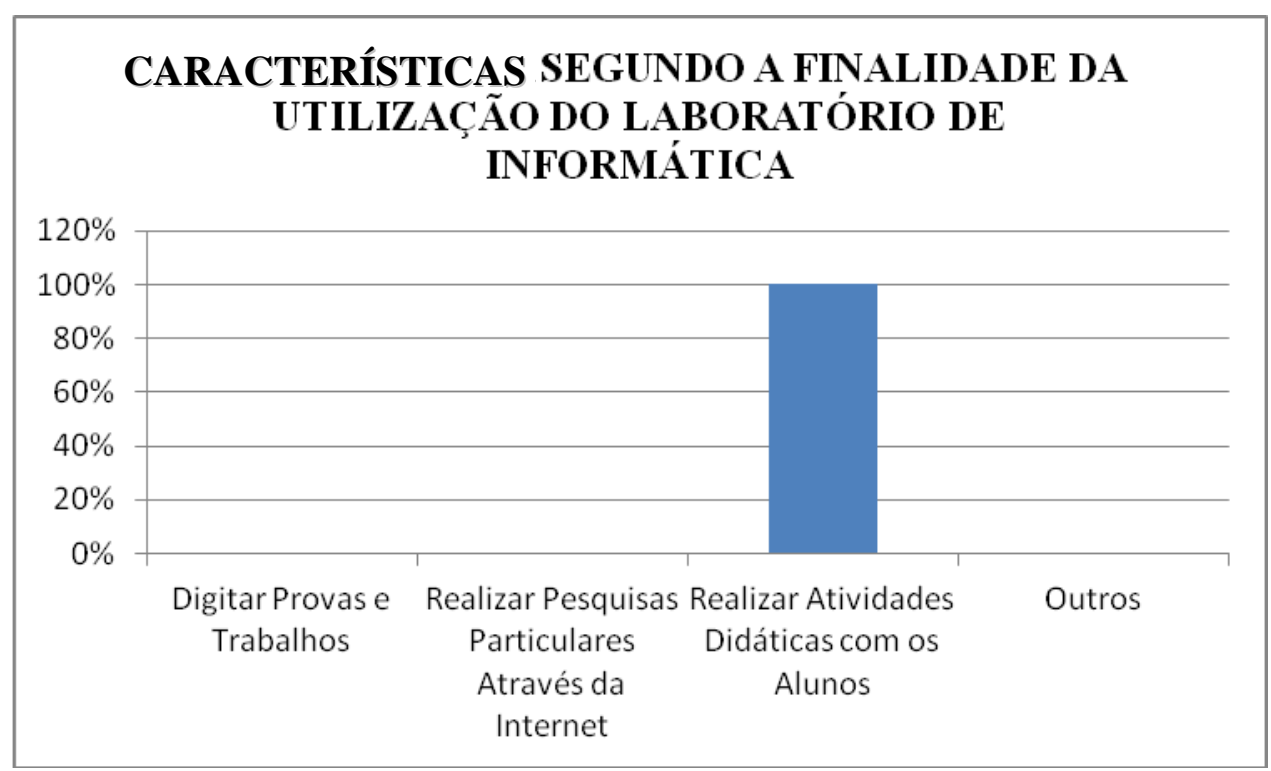

Gráfico 11 - Características Segundo a Finalidade da Utilização do laboratório de Informática. Fonte: Elaborado pelo autor, 2015.

Observa-se através do gráfico que, $100 \%$ dos professores que disseram utilizar o laboratório de informática da escola (75\% da amostra do gráfico 10), o fazem para realizar atividades didáticas com os alunos, sendo que não o utilizam para as outras finalidades apresentadas no gráfico.

\subsection{Características Segundo o Motivo da Não Utilização do Laboratório de Informática}

Identificar os motivos pelos quais os professores não utilizam o laboratório de informática possibilita à unidade escolar trabalhar em prol de resolver os problemas apontados pelos professores para que os mesmos possam utilizar este recurso em suas aulas, pois, bem se sabe que é um instrumento que muito contribui para a aprendizagem dos educandos. 


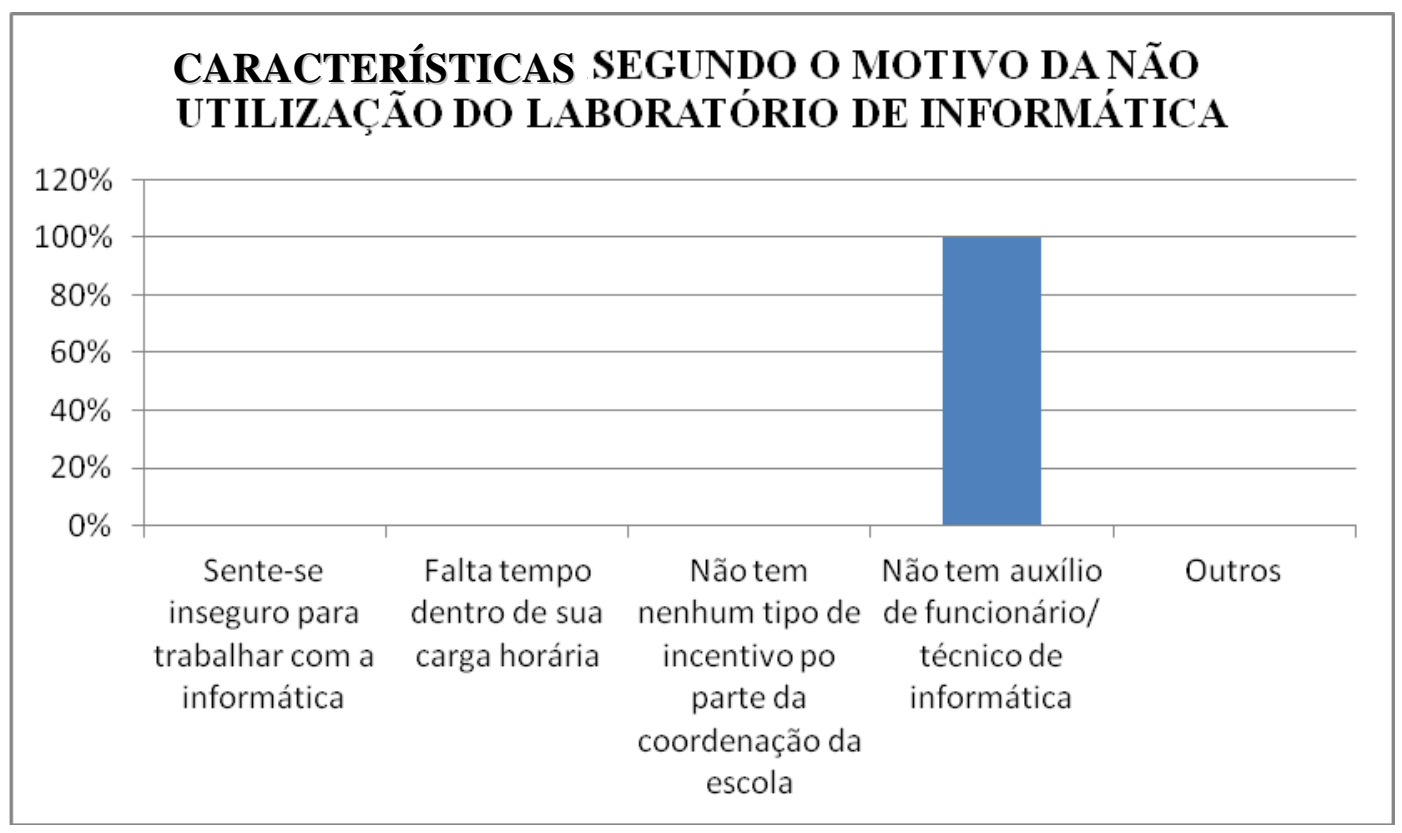

Gráfico 12 - Características Segundo o Motivo da Não Utilização do laboratório de Informática. Fonte: Elaborado pelo autor, 2015.

Verifica-se através do gráfico que $100 \%$ dos professores que disseram não utilizar o laboratório de informática da escola (25\% da amostra do gráfico 10$)$, não o utilizam por não ter auxílio de funcionário (técnico de informática) a disposição no laboratório de informática.

\subsection{Características Segundo o Tipo de Atividade Desenvolvida no Laboratório de Informática}

Identificar o tipo de atividade desenvolvida no laboratório de informática permite que se verifique se este recurso está sendo utilizado para os fins que ele realmente é proposto que é ministrar aulas diferenciadas que contribuam para a formação acadêmica do educando.

Outro fator que se pode se aplicar a este questionário é buscar formas de abranger a utilização do laboratório, utilizá-lo para vários contextos, todos tendo em vista a aprendizagem do educando. 


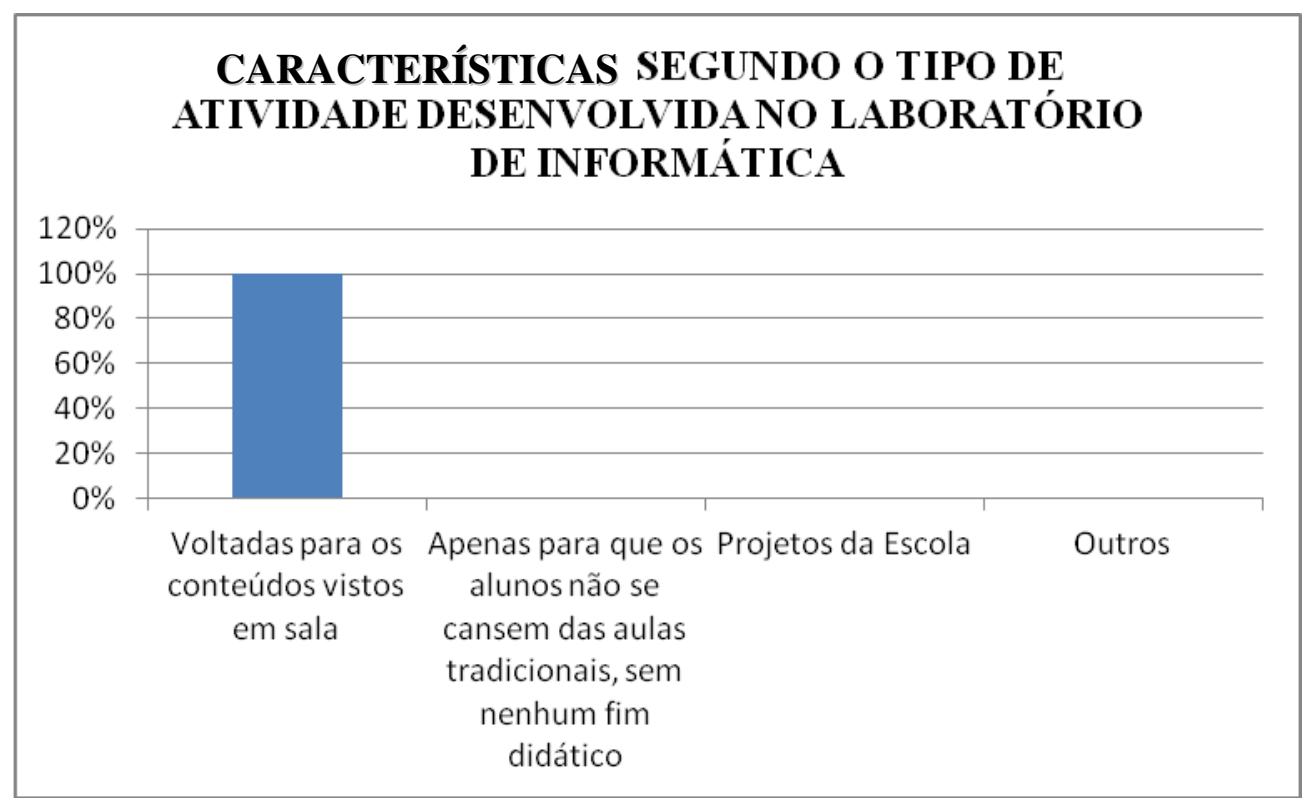

Gráfico 13 - Características Segundo o Tipo de Atividade Desenvolvida no laboratório de Informática. Fonte: Elaborado pelo autor, 2015.

Observa-se que $100 \%$ dos funcionários que utilizam o laboratório de informática (75\% da amostra do gráfico 10), realizam atividades voltadas para os conteúdos vistos em sala, sendo que $0 \%$ o fazem para atender as outras opções apresentadas pelo gráfico.

\subsection{Características Segundo a Melhora dos Alunos com a Utilização do Laboratório de Informática}

A informação obtida através dessa pergunta é o foco principal de todo o questionamento. Todos os instrumentos utilizados pelo educador têm como objetivo principal levar o conhecimento para o educando, e uma das expectativas quando se usa uma tecnologia, como o laboratório de informática é trazer esse conhecimento de forma mais prazerosa para o educando e como resultado final obter uma melhor aprendizagem. 


\section{CONSIDERAÇÕES FINAIS}

Acredito que o uso da informática no processo de ensino, acordado com os objetivos pedagógicos e com as propostas da Lei de Diretrizes e Bases da Educação, visa contribuir com professores e alunos através de métodos mais estimulantes para aprendizagem. Alguns professores ainda têm receio em utilizar o computador nas suas práticas educacionais, o fato é que o uso do computador no ambiente escolar deve auxiliar o processo de aprendizagem e não conduzi-lo.

O computador não é uma ameaça à profissão do professor, seu uso deve ser visto como um instrumento para enriquecer as práticas pedagógicas. Os recursos tecnológicos estão presentes em nossa vida, no âmbito escolar não poderia ser diferente. $\mathrm{O}$ uso da tecnologia como recurso pedagógico, deve estar cada vez, mais presente na vida do professor e do aluno. No entanto pata que isso possa acontecer é necessário que dentro da sala de aula os alunos e docentes se tornem amigos e cúmplices tendo olhar critico, curioso e investigativo desenvolvimento do conhecimento e não uma visão sem compromisso diante dos recursos tecnológicos. 


\section{APÊNDICES}




\section{APÊNDICE A \\ QUESTIONÁRIO EXPLORATÓRIO \\ UNIVERSIDADE FEDERAL DE GOIÁS \\ INSTITUTO DE CIÊNCIAS BIOLÓGICAS \\ ESPECIALIZAÇÃO EM TECNOLOGIAS APLICADAS AO ENSINO DE BIOLOGIA \\ Pesquisadora: Maria Divina de Jesus Silva \\ Orientadora: Aline Neves Vieira de Santana}

\section{QUESTIONÁRIO EXPLORATÓRIO \\ INFORMAÇÕES RELATIVAS A PESQUISA NA ESCOLA}

O objetivo desta pesquisa centra em analisar com que finalidade os professores da Unidade Ensino de Uruana Go utilizam o laboratório de informática nas aulas de ciências e Biologia. Sua cooperação é imprescindível, por isso peço que dedique alguns minutos de seu tempo e responda de maneira reflexiva às questões abaixo. Saiba que você, sua escola e os projetos e atividades nela desenvolvidos não estão em julgamento. Sinta-se livre para anexar cópias de projetos, relatórios de atividades realizadas, fotografias, depoimentos, redações etc., materiais que contribuirão para o enriquecimento da pesquisa. Marque com um (X) as questões objetivas, se necessário escolha mais de uma alternativa.

QUESTIONÁRIO APLICADO AOS PROFESSORES.

1) idade:

2) Há quanto tempo concluiu a graduação:
( ) 1 a 5 anos
( ) 6 a 15 anos
( ) mais de 15 anos

3) Tempo de experiência no magistério: anos.

4) Formação profissional (titulação):

( ) não graduado / graduando

( ) graduado

( ) especialista (pós-graduação) - latu sensu

( ) mestrado

( ) doutorado 
5) Área em que atua:

( ) Ens. Fundamental - séries iniciais

( ) Ens. Fundamental - séries finais

( ) Ens. Médio

( ) Ens. Superior

6) Local de trabalho em que atua:
( ) pública
( ) privada
( ) pública e privada

7) Na graduação recebeu capacitação / aula de informática:
( ) $\mathrm{Sim}$
( ) Não

Como se deu tal capacitação / aula:

8) Como se considera em relação à informática:
( ) sem nenhum conhecimento
( ) usuário médio/
( ) usuário inexperiente
( ) usuário avançado, muito conhecimento

9) Conhece algum software (se sim, descrever se os utiliza e de que maneira):
( ) Cabri - Geómèrtri
( ) não conhece
( ) Maple
( ) Outros

10) Utiliza o laboratório de informática de sua escola para ministrar suas aulas ou outros fins:
( ) $\operatorname{sim}$
( ) não

Se não passe para questão 12

11) Com qual finalidade:

( ) digitar provas e trabalhos

( ) realizar pesquisas particulares através da Internet

( ) realizar atividades didáticas com os alunos

( ) outros 
12) Se não utiliza (ou) o laboratório, qual motivo:

( ) sente-se inseguro para trabalhar com a informática

( ) falta tempo dentro de sua carga horária

( ) não tem nenhum tipo de incentivo por parte da coordenação da escola

( ) não tem auxílio de funcionário / técnico de informática

( ) outros

13) Que tipo de atividade desenvolve com seus alunos no laboratório de informática:

( ) voltadas para os conteúdos vistos em sala

( ) apenas para que os alunos não se cansem das aulas tradicionais, sem nenhum fim didático

( ) projetos da escola

( ) outros, descreva:

14) É possível verificar se houve melhora por parte dos alunos com a utilização do laboratório, em que sentido:

( ) aprendizado

( ) comportamento

( ) não houve melhora

15) O que o motivou a esse tipo de capacitação?

( ) as atividades em sala tem melhor rendimento

( ) outros

16) Quando fez a ultima atualização em informática: Mês / ano: 1 


\title{
APÊNDICE B \\ CARTA DE APRESENTAÇÃO DA PESQUISA
}

\author{
UNIVERSIDADE FEDERAL DE GOIÁS \\ INSTITUTO DE CIÊNCIAS BIOLÓGICAS \\ ESPECIALIZAÇÃO EM TECNOLOGIAS APLICADAS AO ENSINO DE \\ BIOLOGIA \\ Pesquisadora: Maria Divina de Jesus Silva \\ Orientadora: Aline Neves Vieira de Santana
}

\section{CARTA DE APRESENTAÇÃO DA PESQUISA \\ Prezado(a): Diretor(a) do Colégio Estadual Zico Monteiro}

Esta pesquisa, Contribuições do Laboratório de Informática nas aulas de ciências e Biologia: um estudo de caso da unidade de ensino de Uruana Go, coletará dados por meio de um questionário entregue aos professores da Unidade educacional. A investigação intenta analisar com que finalidade os professores de ciências da Unidade de Ensino de Uruana Go utilizam o laboratório de informática.

Em qualquer etapa do estudo, você terá acesso ao investigador para esclarecimento de eventuais dúvidas. Sou Maria Divina de Jesus Silva, aluna da Especialização em TecnologiasAplicadas ao Ensino de Biologia meus contatos são: (62) 8594-2549 e endereço eletrônico: mdivinajs@gmail.com

É garantida aos sujeitos participantes da pesquisa a liberdade da retirada do consentimento e o abandono do estudo a qualquer momento.

As informações obtidas serão analisadas em conjunto com os outros sujeitos da pesquisa, não sendo divulgada a identificação de nenhum participante. Fica assegurado, também, o direito de ser mantido atualizado sobre os resultados parciais da pesquisa, assim que a análise dos dados chegarem ao conhecimento do pesquisador.

Não há despesas pessoais para o participante em qualquer fase do estudo. Também não há compensação financeira relacionada à sua colaboração. Se existir qualquer despesa adicional, ela será absorvida pelo orçamento da pesquisa.

Comprometo-me, como pesquisador principal, a utilizar os dados e o material coletados somente para esta investigação. 


\author{
APÊNDICE C \\ TERMO DE CONSENTIMENTO LIVRE E ESCLARECIDO
}

\author{
UNIVERSIDADE FEDERAL DE GOIÁS \\ INSTITUTO DE CIÊNCIAS BIOLÓGICAS \\ ESPECIALIZAÇÃO EM TECNOLOGIAS APLICADAS AO ENSINO DE \\ BIOLOGIA
}

Pesquisadora: Maria Divina de Jesus Silva

Orientadora: Aline Neves Vieira de Santana

TERMO DE CONSENTIMENTO INFORMADO (TCI)

Pelo presente consentimento, eu,

portador do $\mathrm{CPF}$,

e $\mathrm{RG}$,

, declaro que fui

informado (a), de forma clara e detalhada, dos objetivos e da justificativa da Pesquisa intitulada "Contribuições do Laboratório de Informática nas aulas de ciências e Biologia: um estudo de caso da unidade de ensino de Uruana Go", a ser desenvolvida no período de agosto a fevereiro de 2015. Tenho Ciência que terei o conhecimento de que receberei resposta a qualquer dúvida sobre os procedimentos e outros assuntos relacionados com esta investigação. Entendo que os professores dessa instituição não serão identificados e que se manterá o caráter confidencial das informações registradas relacionadas com a privacidade dos participantes da pesquisa. Ainda foi-me garantido que posso retirar meu consentimento a qualquer momento. Concordo com a participação neste estudo, bem como autorizo para fins exclusivamente desta pesquisa e de seus frutos, a utilização de informações coletadas (entrevistas, questionários, áudios e imagens) nesta pesquisa.

Assinatura do participante da pesquisa

Maria Divina de Jesus Silva

Pesquisadora responsável 


\section{REFERÊNCIAS}

ALMEIDA, M. E. B. Gestão de Tecnologias, mídias e recursos na escola: O Compartilhar da SBPC, Belém, n. 58, p.1-2004.

BARDIN, L. Análise de Conteúdo. Lisboa: Edições 70, 2010.

BORGES, Marcia de Freitas Vieira. Inserção da informática no ambiente escolar: inclusão digital e laboratórios. XXVII Congresso da SBPC, Belém, n. 58 p. 1-2008.

BARROS, C. S. G. Pontos de Psicologia Escolar. São Paulo: Editora Ática: 1998.

CHIZZOTTI, A. Pesquisa em ciências humanas e sociais. 2 ed. São Paulo: Cortez, 1995.

GIL, A. C. Métodos e técnicas de pesquisa social. 1 ed. - São Paulo: Atlas,1995.

FARIA, E. T. O professor e as novas tecnologias. In: ENRICONE, Délcia (Org.). Ser Professor, EDIPUCRS: Porto Alegre, 2004. p. 57-72.

KENSKI, V. M. O Ensino e os recursos didáticos em uma sociedade cheia de tecnologias. In: VEIGA, I. P. A. (org). Didática: o Ensino e suas relações. Campinas, SP: Papirus, 1996.

LÜDKE, M.; ANDRÉ, M. E. D. A. Pesquisa em Educação: Abordagens Qualitativas. São Paulo: EPU, 1986.

MARCONI, M. A.; LAKATOS, E. M. Fundamentos de Metodologia Científica. $5^{\text {a }}$ ed. São Paulo: Atlas, 2003.

OLIVEIRA, S. L. Tratado de metodologia científica: projetos de pesquisas, TGI, TCC, monografias, dissertações e teses. São Paulo: Pioneira Thomson Learnig, 2002.

PINTO, A. M. As novas tecnologias e a educação. Rio de Janeiro, v.35, n.1, p.1-7. 1997.

PERES, H. H. C. et al. Estudo exploratório sobre utilização dos recursos de informática por alunos do curso de graduação em enfermagem, n. 88, 2001.

ROCHA, S. S. D. O uso do Computador na Educação: a informática Educativa. Revista Espaço Acadêmico, São Paulo, n. 85, p.1- 2001.

ROESCH, S. M. A. Projetos de estágio e de pesquisa em administração: guia para estágios, trabalhos e conclusão, dissertações e estudos de caso. 3 ed. São Paulo: Atlas, 2006. 